\title{
Growth of Pseudomonas putida F1 on styrene requires increased catechol-2,3-dioxygenase activity, not a new hydrolase
}

\begin{abstract}
Correspondence
Anthony G. Hay

agh5@cornell.edu
\end{abstract}

Received 23 June 2010

Revised 30 September 2010

Accepted 6 October 2010

\author{
Kevin W. George, ${ }^{1,2}$ Jeanne Kagle, ${ }^{2} \dagger$ Lauren Junker, ${ }^{2} \ddagger$ Amy Risen ${ }^{1,2}$ \\ and Anthony G. Hay ${ }^{1,2}$ \\ ${ }^{1}$ Field of Environmental Toxicology, Cornell University Ithaca, NY 14850, USA \\ ${ }^{2}$ Department of Microbiology, Cornell University Ithaca, NY 14850, USA
}

\section{INTRODUCTION}

Much is known about the mechanisms by which bacteria degrade aromatic compounds (reviewed by Díaz, 2004). However, even in model systems we still have much to learn about the determinants of growth substrate specificity. The toluene degradation (tod) pathway in Pseudomonas putida F1 (Gibson et al., 1968) serves as a prototypical model for aromatic hydrocarbon degradation (Zylstra \& Gibson, 1989; Zylstra et al., 1988) (Fig. 1). Multiple substrates are capable

tPresent address: Department of Biology, Mansfield University of Pennsylvania, Mansfield, PA 16933, USA.

†Present address: Johnson and Johnson Consumer Product Worldwide, 185 Tabor Rd, Morris Plains, NJ 07950, USA.

Abbreviations: 6-vinyl HODA, 2-hydroxy-6-vinylhexa-2,4-dienoate; 6methyl HODA, 2-hydroxy-6-oxo-methylhexa-2,4-dienoate; C230, catechol-2,3-dioxygenase; MFP, meta-fission product.

Four supplementary figures and a supplementary table detailing the PCR primers used in this study are available with the online version of this paper. of inducing the tod operon, although only a subset of these compounds support growth (Cho et al., 2000; Lacal et al., 2006).

In the tod operon, initial dioxygenation of toluene is performed by the multi-component toluene dioxygenase, a versatile enzyme encoded by todC1C2BA (Jiang et al., 1999, 1996; Yeh et al., 1977; Zylstra \& Gibson, 1989). Following dioxygenation, dehydrogenation of the cis-dihydrodiol leads to 3-methylcatechol production. TodE (3-methylcatechol 2,3-dioxygenase) catalyses cleavage of this substrate, forming the yellow-coloured meta-fission product (MFP) 2-hydroxy6-oxo-methylhexa-2,4-dienoate (6-methyl HODA), which is then hydrolysed to acetic acid and 2-hydroxypenta-2,4dienoate by TodF. After hydrolysis, TodG, TodH and TodI further degrade the pentadienoate to form pyruvate and acetate (Zylstra et al., 1988). The entire catabolic todXFC1C2BADEGIH operon is transcribed from a single promoter designated $\mathrm{P}_{\text {todX }}$. Transcriptional activation of this promoter is mediated by TodS and TodT, a constitutively expressed, two-component system located downstream of 


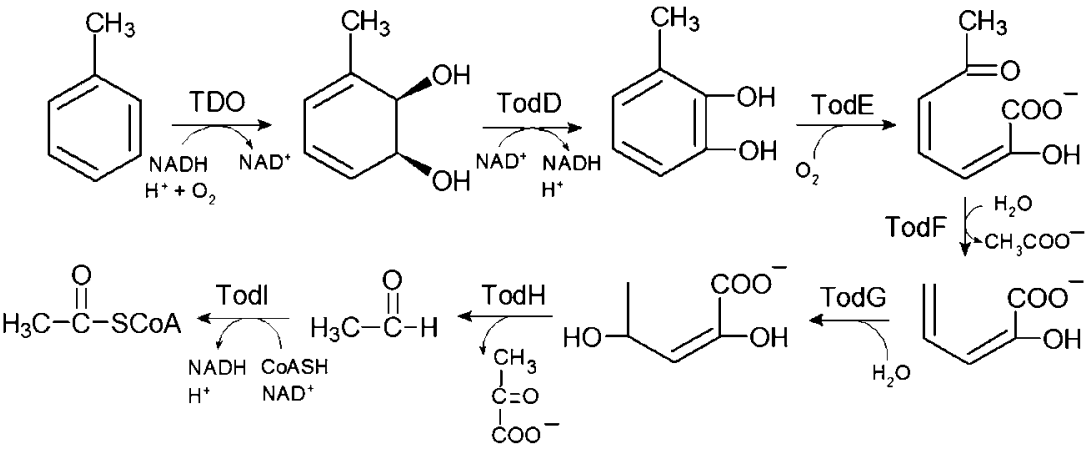

Fig. 1. Pathway of toluene degradation by enzymes of the tod operon. Based on a figure by Zylstra et al. (1988). See text for details.
todH (Busch et al., 2007; Lacal et al., 2006, 2008; Lau et al., 1997; Mosqueda et al., 1999).

Studies of F1 and related P. putida strains expressing the tod pathway have implicated TodF (6-methyl HODA hydrolase) as a key determinant of growth substrate specificity, particularly in the metabolism of biphenyl and n-alkyl benzenes (Cho et al., 2000; Choi et al., 2003; Furukawa et al., 1993; Ohta et al., 2001; Seah et al., 1998, 2000). In several cases, it has been shown that expression of an alternative MFP hydrolase is sufficient to allow these strains to grow on biphenyl (Choi et al., 2003; Furukawa et al., 1993; Ohta et al., 2001). Analysis of available MFP hydrolase crystal structures has revealed a conserved, structural basis for the strict substrate specificity of these enzymes and underlined their importance in aromatic degradation pathways (Fushinobu et al., 2002; Habe et al., 2003; Nandhagopal et al., 2001).

Mechanism-based inactivation of catechol-2,3-dioxygenases (C23Os) has been implicated as another potential determinant of growth substrate specificity (Bartels et al., 1984; Cerdan et al., 1994; Klecka \& Gibson, 1981; Ramos et al., 1987; Rojo et al., 1987; Vaillancourt et al., 2002). Inactivation of $\mathrm{C} 23 \mathrm{O}$ s during substrate cleavage appears to involve primarily accidental oxidation of active-site $\mathrm{Fe}$ (II) to $\mathrm{Fe}(\mathrm{III})$ (Cerdan et al., 1994; Vaillancourt et al., 2002). Mechanism-based inactivation has been demonstrated most often with chlorocatechols, but para-substituted alkyl catechols can also exert a similar effect (Vaillancourt et al., 2006). Inactivation of this type has been shown to limit the substrate range of toluates degraded by the TOL pathway, polychlorinated biphenyls degraded by the $b p h$ pathway and chlorobenzenes degraded by the tod pathway (Cerdan et al., 1994; Klecka \& Gibson, 1981; Ramos et al., 1987; Rojo et al., 1987; Vaillancourt et al., 2002; Ward et al., 2004).

In vitro, enzymic inactivation of $\mathrm{C} 23 \mathrm{O}$ s can be reversed by treatment with reducing agents or incubation under anaerobic conditions with $\mathrm{Fe}(\mathrm{II})$ (Vaillancourt et al., 2006). In vivo, some organisms appear to utilize separate proteins, [2Fe-2S] plant-like ferredoxins, to reactivate oxidized $\mathrm{C} 23 \mathrm{O}$ s and restore proper function. This has been most clearly demonstrated in the case of XylT, a novel plant-like $[2 \mathrm{Fe}-2 \mathrm{~S}]$ ferredoxin in the TOL pathway that has been shown to reactivate $\mathrm{XylE}$, a $\mathrm{C} 23 \mathrm{O}$ homologous to TodE (Hugo et al., 1998, 2000; Polissi \& Harayama, 1993). Similar enzymes are encoded in other aromatic degradation operons including DmpQ, a XylT-like ferredoxin in the $d m p$ operon encoding the metabolism of phenols in Pseudomonas sp. CF600 (Powlowski \& Shingler, 1994). Like XylT, DmpQ is capable of reactivating XylE, suggesting a conserved mechanism of action for [2Fe-2S] ferredoxins (Hugo et al., 2000). By serving as a natural repair system in aromatic degradation pathways, it is likely that $[2 \mathrm{Fe}-2 \mathrm{~S}]$ ferredoxins play key roles in augmenting the range of growth substrates in numerous organisms.

Despite its structural similarity to ethylbenzene, which can be used by F1 for growth, styrene does not support growth of $\mathrm{F} 1$ even though it induces the tod operon to moderate levels (Cho et al., 2000; Lacal et al., 2006). The observed accumulation of yellow MFP by F1 exposed to styrene, along with reportedly low levels of F1 MFP hydrolase activity toward the styrene MFP, has previously led to the supposition that TodF functions as an enzymic block in styrene metabolism (Cho et al., 2000). There are, however, no published reports on the kinetics of styrene MFP hydrolysis. Here, we present a kinetic analysis of the styrene MFP hydrolase activity of TodF and provide evidence that its substrate specificity does not limit styrene metabolism as previously suggested. Instead, we demonstrate that 3vinylcatechol inactivates TodE, the meta-cleaving $\mathrm{C} 23 \mathrm{O}$ in the tod operon, and suggest that substrate-level inactivation of this $\mathrm{C} 23 \mathrm{O}$ is the limiting metabolic factor which prevents F1 from growing on styrene. Together, these data suggest an expanded role for $\mathrm{C} 23 \mathrm{O}$ inactivation as a key determinant of growth substrate specificity during the degradation of aromatics.

\section{METHODS}

Strains and growth conditions. P. putida F1 and its plasmidcarrying derivatives were grown at $30{ }^{\circ} \mathrm{C}$ in Luria-Bertani medium (LB) supplemented with appropriate antibiotics $(25 \mathrm{mg}$ chloramphenicol $1^{-1}$ or $150 \mathrm{mg}$ ampicillin $\mathrm{l}^{-1}$ ) or minimal salts medium (MSM) (Focht, 1994) containing suitable growth substrates. Toluene or styrene was provided in vapour phase for growth on agar plates or at a concentration of $5 \mathrm{mM}$ in liquid media. When specified, acetate was supplied at a concentration of $20 \mathrm{mM}$. Escherichia coli JM109 
(Yanisch-Perron et al., 1985) and S17 (de Lorenzo \& Timmis, 1994) strains were grown at $37{ }^{\circ} \mathrm{C}$ in $\mathrm{LB}$ containing $15 \mathrm{mg}$ nalidixic acid $\mathrm{l}^{-1}$ and $50 \mathrm{mg}$ streptomycin $\mathrm{l}^{-1}$, respectively. Strains containing pBBR1MCS-5 and derivatives were selected on medium containing $25 \mathrm{mg}$ gentamicin $\mathrm{l}^{-1}$.

Plasmid and strain construction. The plasmid vectors used in this work are described in Table 1. Specific primers for genes in the tod and $d m p$ operons were designed based on available P. putida F1 (GenBank accession no. NC_009512) and Pseudomonas sp. CF600 (GenBank accession nos X60835 and X60836) (Shingler et al., 1992) sequences, respectively (Supplementary Table S1, available with the online version of this paper). PCR was performed by using the HotStart Master Mix kit from Qiagen and a PTC-200 DNA Engine thermocycler from MJ Research. PCR fragments were digested with appropriate enzymes and ligated into pBBRMCS $-5\left(\mathrm{Gm}^{\mathrm{R}}\right)$ or pRSET$A\left(A m p^{R}\right)$ by using T4 DNA ligase (Promega). The resultant plasmids were transformed into appropriate hosts by electroporation. Transformants were selected on LB plates containing antibiotics and screened by PCR.

GC-MS detection of 3-vinylcatechol. F1 was grown for $48 \mathrm{~h}$ on MSM styrene+acetate. After removal of cells via centrifugation $\left(10000 \mathrm{~g}\right.$ at $4{ }^{\circ} \mathrm{C}$ for $10 \mathrm{~min}$ ), intermediates in the supernatant were derivatized with $1.5 \% \mathrm{~K}_{2} \mathrm{CO}_{3}$ and $0.5 \%$ acetic anhydride (Baker et al., 1994). Following extraction with chloroform, samples were analysed on a Hewlett Packard 6890 GC coupled to an HP 5973 MS detector. An HP-5MS column $(29.2 \mathrm{~mm} \times 0.25 \mathrm{~mm} \times 0.25 \mu \mathrm{m})$ was used with a temperature range of $60-300{ }^{\circ} \mathrm{C}$ at a ramp of $30{ }^{\circ} \mathrm{C} \mathrm{min}{ }^{-1}$.

Biosynthesis of 3-vinylcatechol and MFPs. JM109 (pDTG601) (pTodD) and S17 (pDmpB) were grown overnight in LB and diluted $1: 100$ into fresh media of the same type. At mid-exponential phase $\left(\mathrm{OD}_{600}=0.4\right)$, IPTG was added to a concentration of $1 \mathrm{mM}$. Following a $3 \mathrm{~h}$ induction, cultures were washed and resuspended in $30 \mathrm{mM} \mathrm{K}_{3} \mathrm{PO}_{4}$ buffer ( $\mathrm{pH}$ 7.0). For synthesis of 3-vinylcatechol, a suspension of JM109 (pDTG601) (pTodD) was exposed to $1 \mathrm{mM}$ styrene and incubated for $8 \mathrm{~h}$ at $37{ }^{\circ} \mathrm{C}$. The supernatant was then harvested following centrifugation $\left(10000 \mathrm{~g}\right.$ at $4{ }^{\circ} \mathrm{C}$ for $\left.15 \mathrm{~min}\right)$, filter-sterilized and kept on ice prior to use. The purity of 3vinylcatechol was $>99 \%$ as determined via GC-MS. For synthesis of 6-methyl HODA and 2-hydroxy-6-vinylhexa-2,4-dienoate (6-vinyl HODA), toluene or styrene was added in the vapour phase to a $1: 1$ co-culture of JM109 (pDTG601) (pTodD) and S17 (pDmpB) until the suspension turned deep yellow, indicating the presence of concentrated MFP. Final concentrations of 6-methyl HODA and 6-vinyl HODA were determined spectrophotometrically by measuring absorbance at 389 and $425 \mathrm{~nm}$, respectively. A reported absorption coefficient of $11.9 \mathrm{mM}^{-1} \mathrm{~cm}^{-1}$ was used for 6-methyl HODA and verified experimentally, while an absorption coefficient of $10.7 \mathrm{mM}^{-1} \mathrm{~cm}^{-1}$ was calculated for 6-vinyl HODA.

Preparation of cell-free extracts. $P$. putida F1 and its derivatives were grown overnight at $30{ }^{\circ} \mathrm{C}$ on MSM acetate with toluene present in the vapour phase as an inducer. JM109 (pTodF) was grown overnight in LB, inoculated 1:100 into fresh medium and induced with $1 \mathrm{mM}$ IPTG at an $\mathrm{OD}_{600}$ of 0.4 . Following induction, cell suspensions were washed and resuspended in sonication buffer (100 mM Tris/HCl, $10 \mu \mathrm{M}$ PMSF, $1 \mu \mathrm{M}$ DTT, pH 8) and lysed through sonication. Supernatants were harvested after centrifugation for $15 \mathrm{~min}\left(12000 \mathrm{~g}\right.$ at $\left.4{ }^{\circ} \mathrm{C}\right)$. Protein concentrations of cell-free extracts were determined with a Bradford protein assay (Bio-Rad) following the manufacturer's instructions. Extracts were stored at $-20{ }^{\circ} \mathrm{C}$ in $50 \%$ glycerol until use.

Purification of His-tagged TodF. E. coli BL21(DE3) pLysS (pRSET$\left.\mathrm{A}: \operatorname{TodF}_{\mathrm{His}}\right)$ was grown overnight at $37{ }^{\circ} \mathrm{C}$, inoculated $1: 50$ into $500 \mathrm{ml}$ fresh SOB media (Hanahan, 1983) and induced with $1 \mathrm{mM}$ IPTG at an $\mathrm{OD}_{600}$ of 0.4 . After $16 \mathrm{~h}$ incubation at $37{ }^{\circ} \mathrm{C}$ under gentle shaking, cells were harvested by centrifugation $\left(10000 \mathrm{~g}\right.$ at $\left.4{ }^{\circ} \mathrm{C}\right)$ for $10 \mathrm{~min}$ and resuspended in lysis equilibration wash (LEW) buffer (50 mM NaH $\mathrm{PO}_{4}, 300 \mathrm{mM} \mathrm{NaCl}, \mathrm{pH} \mathrm{8.0)}$. Prior to lysis by sonication, the cell suspension was placed on ice and incubated with lysozyme $\left(0.2 \mathrm{mg} \mathrm{ml}^{-1}\right)$ for $30 \mathrm{~min}$ with gentle mixing. Crude lysate was collected following centrifugation $\left(12000 \mathrm{~g}\right.$ at $\left.4{ }^{\circ} \mathrm{C}\right)$ for $15 \mathrm{~min}$ and added to $0.5 \mathrm{~g}$ Prepease (USB) nickel resin. Protein-bound resin was separated through gravity sedimentation and washed three times with $15 \mathrm{ml}$ LEW buffer. Three $5 \mathrm{ml}$ aliquots of LEW buffer containing $250 \mathrm{mM}$ imidazole were used to elute TodF $\mathrm{His}_{\text {. }}$

\section{Enzyme assays}

MFP degradation. Degradation of MFPs was quantified by measuring the rate of decrease in absorbance at room temperature. Wavelengths of 389 and $425 \mathrm{~nm}$ were used for 6-methyl HODA and 6-vinyl HODA, respectively. Concentrations of MFP were estimated by using the appropriate absorption coefficients. Degradation assays were performed at $25{ }^{\circ} \mathrm{C}$ in a 96 -well plate format by using cell-free extracts in triplicate. Initial degradation rates were measured and standardized to protein content for comparisons between strains.

Determination of kinetic parameters. The kinetic parameters of purified $\mathrm{TodF}_{\mathrm{His}}$ were determined through measurement of initial

Table 1. Plasmids used in this study

\begin{tabular}{|c|c|c|}
\hline Plasmid & Characteristics & Reference \\
\hline pRSET A & $A m p^{R}$, high level protein expression vector for $\mathrm{Ni}^{2+}$ affinity purification & Kroll et al. (1993) \\
\hline pDmpB & Derivative of pBBR1MCS-5 containing $d m p B$, DmpB expression vector & This study \\
\hline pDmpQB & Derivative of pBBR1MCS-5 containing $d m p Q B$, DmpQB expression vector & This study \\
\hline pDmpQ & Derivative of pBBR1MCS-5 containing $d m p Q$, DmpQ expression vector & This study \\
\hline pTodD & Derivative of pBBR1MCS-5 containing todD, TodD expression vector & This study \\
\hline pRSET-A: TodF ${ }_{\text {His }}$ & $\begin{array}{l}\text { Derivative of pRSET A containing todF for generation of an N-terminal His-tagged } \\
\text { fusion protein }\end{array}$ & This study \\
\hline pDTG601 & $\begin{array}{l}\text { Derivative of pKK223-3 containing todC1C2BA, used for generation of 3-vinylcatechol } \\
\text { and 3-methylcatechol }\end{array}$ & Zylstra \& Gibson (1989) \\
\hline
\end{tabular}


degradation rates with varying concentrations of 6-methyl HODA or 6-vinyl HODA. Graphpad Prism 5 (Graphpad Software) was used to calculate $K_{\mathrm{m}}$ and $k_{\text {cat }}$ based on a least-squares analysis of MichaelisMenten plots.

Measuring C230 activity. $\mathrm{C} 23 \mathrm{O}$ activity was measured spectrophotometrically as an increase in absorbance at $375 \mathrm{~nm}$ following the addition of $2 \mathrm{mM}$ catechol to whole-cell suspensions. For E. coli strains harbouring $\mathrm{C} 23 \mathrm{Os}, \mathrm{C} 23 \mathrm{O}$ activity was also measured by using 3-vinylcatechol in addition to non-substituted catechol as a substrate. In these cases, absorbance increase was measured at $425 \mathrm{~nm}$. Briefly, induced cells were washed and resuspended in $30 \mathrm{mM} \mathrm{K}_{3} \mathrm{PO}_{4}$ buffer and assayed in triplicate with a Bio-Tek Synergy HT-I microplate reader. For F1 strains, induction was achieved by exposing acetate-grown cells to toluene for 8 h. E. coli strains were induced for $4 \mathrm{~h}$ with $1 \mathrm{mM}$ IPTG. Following the addition of catechol, initial rates of MFP production were calculated and correlated with protein content. Concentrations of catechol MFP were estimated by using a reported absorption coefficient of $40 \mathrm{mM}^{-1} \mathrm{~cm}^{-1}$ (Seah et al., 1998).

C230 inactivation assays. Induced cells (see above) were collected by centrifugation and washed in $30 \mathrm{mM} \mathrm{K} \mathrm{K}_{3} \mathrm{PO}_{4}$ buffer. When working with styrene or toluene, triplicate cultures were exposed to $2 \mathrm{mM}$ of the substrate. With 3-vinylcatechol and 3-methylcatechol, F1 cultures were resuspended in filtered supernatant containing $100 \mu \mathrm{M}$ substrate. To generate dose-response curves, a range of 3 vinylcatechol concentrations was added to resting cultures. At set time points, $1 \mathrm{ml}$ aliquots were taken, centrifuged at $16000 \mathrm{~g}$ for $1 \mathrm{~min}$ and resuspended in an equal volume of $30 \mathrm{mM} \mathrm{K}_{3} \mathrm{PO}_{4}$ buffer. $\mathrm{C} 23 \mathrm{O}$ activity was measured as described above.

Quantification of growth on styrene. Due to optical interference from coloured metabolites, growth of recombinant F1 strains on styrene was assessed by c.f.u. counts rather than $\mathrm{OD}_{600}$. F1 and related strains were grown overnight in MSM + acetate, washed twice in $30 \mathrm{mM} \mathrm{K} \mathrm{PO}_{4}$ buffer and inoculated 1:100 into MSM containing $5 \mathrm{mM}$ styrene. At set time points, $100 \mu \mathrm{l}$ aliquots were taken and serially diluted in sterile $30 \mathrm{mM} \mathrm{K}{ }_{3} \mathrm{PO}_{4}$ buffer. Five microlitres of each dilution was spotted onto LB agar and individual colonies were counted after overnight incubation at $30{ }^{\circ} \mathrm{C}$.

\section{RESULTS}

\section{F1 exposed to styrene accumulates 3-vinylcatechol}

When toluene-induced F1 resting cultures were exposed to styrene vapours, a yellow compound was observed in the culture medium (data not shown). The accumulation of a yellow MFP, putatively identified as 6-vinyl HODA, was previously reported when F1 was exposed to styrene (Cho et al., 2000). Spectral analysis yielded an absorbance maximum of approximately $425 \mathrm{~nm}$, similar to the value of $419 \mathrm{~nm}$ reported by Cho et al. (2000). Its accumulation was transient, however, and after approximately $48 \mathrm{~h}$ the culture had turned a deep, opaque brown (Supplementary Fig. S1, inset). In resting cells exposed to toluene, no such colour was evident. Given that catechol polymerization products are typically brown or black, it was hypothesized that 3-vinylcatechol had accumulated in the culture media and subsequently polymerized. GC/MS analysis of chloroform extracts of the acetylated supernatant revealed a single, large peak with a mass spectrum consistent with acetylated 3-vinylcatechol (Supplementary Fig. S1). No catecholic intermediates were detected in cells exposed to toluene (data not shown). The accumulation of 3vinylcatechol suggested that TodE, the $\mathrm{C} 23 \mathrm{O}$ responsible for cleaving this intermediate, might be inactivated during styrene metabolism. The failure to detect 6-vinyl HODA suggested that this metabolite might be degraded by TodF, although lack of detection could have been due to poor extraction efficiency or inadequate instrument sensitivity. To clarify the role of TodF in styrene metabolism, analyses of F1 cell-free extracts and purified TodF were performed.

\section{TodF catalyses the efficient transformation of 6-vinyl HODA}

To determine if the reported inability of TodF to degrade the styrene MFP (Cho et al., 2000) prevented growth on styrene, cell-free extracts of toluene-induced F1 were exposed to biologically synthesized 6-vinyl HODA. Interestingly, F1 degraded 6-vinyl HODA at a considerably higher rate than previously reported (Cho et al., 2000) (Supplementary Fig. S2a). To confirm that TodF was responsible for the observed activity, a todF expression vector was constructed (pTodF) and expressed in E. coli JM109. Consistent with our initial results, cell-free extracts of induced JM109 (pTodF) rapidly transformed 6-vinyl HODA (Supplementary Fig. S2b). Both the wild-type- and the plasmid-borne copies of todF were sequenced and found to be $100 \%$ identical to the previously published sequence (GenBank accession no. M64080) (Menn et al., 1991). To assess TodF activity in vitro, purified TodF $_{\mathrm{His}}$ (Fig. 2, Table 2) was assayed with 6-methyl HODA and 6vinyl HODA, the ring-fission products of toluene and styrene, respectively. When exposed to both substrates, TodF $_{\text {His }}$ followed classical Michaelis-Menten kinetics (Fig. 2 ). Interestingly, the $K_{\mathrm{m}}$ calculated for 6-vinyl HODA $(20 \mu \mathrm{M})$ was significantly lower than that for 6-methyl HODA $(31 \mu \mathrm{M})$, indicating increased enzyme affinity for 6-vinyl HODA. The $k_{\text {cat }}$ for 6-vinyl HODA, however, was more than six times lower than that for 6-methyl HODA $\left(4.8\right.$ versus $\left.32 \mathrm{~s}^{-1}\right)$. The $k_{\mathrm{cat}} / K_{\mathrm{m}}$ values for both substrates indicated that TodF degraded 6-methyl HODA approximately four times more efficiently than 6-vinyl HODA.

\section{C230 activity is abolished in P. putida F1 exposed to styrene and 3-vinylcatechol}

That TodF was able to degrade 6-vinyl HODA relatively efficiently suggested that this enzyme was not limiting growth of F1 on styrene. Based on the previously observed accumulation of 3-vinylcatechol, it was hypothesized that styrene metabolism resulted in the abrogation of $\mathrm{C} 23 \mathrm{O}$ activity in growing $\mathrm{F} 1$ cells. To test this hypothesis, resting cultures of toluene-induced F1 were exposed to styrene and its intermediate 3-vinylcatechol, and assayed for $\mathrm{C} 23 \mathrm{O}$ activity. Interestingly, within $1 \mathrm{~h}$ of exposure to styrene, $\mathrm{C} 23 \mathrm{O}$ activity was reduced sevenfold in toluene-induced 

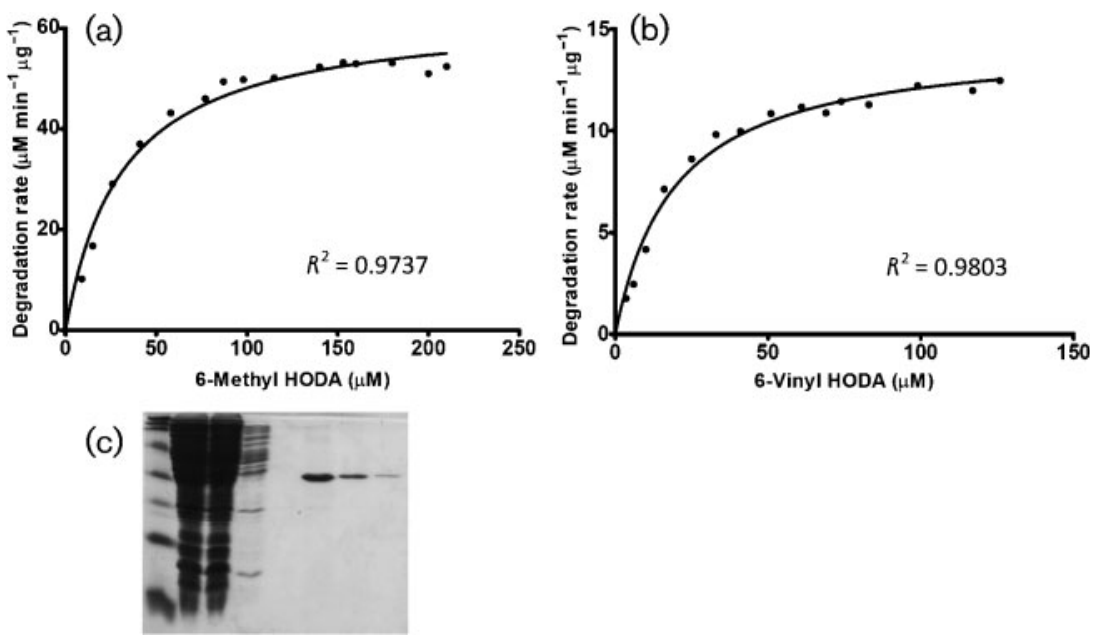

Fig. 2. $\operatorname{TodF}_{\mathrm{His}}$ Michaelis-Menten kinetics. TodF $_{H i s}$ is capable of degrading 6-vinyl HODA, albeit less efficiently than 6-methyl HODA. These curves represent a leastsquares fit of the Michaelis-Menten equation to degradation rates of 6-methyl HODA (a) and 6-vinyl HODA (b). Kinetic parameters for the two substrates are listed in Table 2. (c) SDS-PAGE separation of $\mathrm{TodF}_{\mathrm{His}}$ purification.

cells (Fig. 3a). Exposure of similarly induced cells to toluene caused no such inactivation. 3-Vinylcatechol, the substrate directly cleaved by TodE, was an even more potent inhibitor and appeared to abolish $\mathrm{C} 23 \mathrm{O}$ activity completely within $2 \mathrm{~h}$ (Fig. 3a). Inactivation appeared to be concomitant with the appearance of 6-vinyl HODA (data not shown). 3-Methylcatechol generated from toluene served as a control and had no effect on C23O activity.

To determine if 3-vinylcatechol was the actual inhibitor of $\mathrm{C} 23 \mathrm{O}$ activity and if metabolism of styrene to 3vinylcatechol was required for $\mathrm{C} 23 \mathrm{O}$ inactivation, a todE expression vector (pTodE) was constructed and expressed in E. coli S17. The resultant strain was then exposed to either styrene or 3-vinylcatechol. As expected, C23O activity in S17 (pTodE) was abrogated by exposure to 3vinylcatechol, but was unaffected by styrene (Fig. 3b). The relevant controls of toluene and 3-methylcatechol had no effect on $\mathrm{C} 23 \mathrm{O}$ activity.

\section{Expression of DmpQB and TodE in trans permits growth on styrene}

Given that $\mathrm{C} 23 \mathrm{O}$ inactivation was implicated as being responsible for the inability of F1 to grow on styrene, it was hypothesized that increasing the levels of $\mathrm{C} 23 \mathrm{O}$ activity through the expression of plasmid-borne genes and/or expression of a plant-like ferredoxin would permit F1 to use styrene as a growth substrate.
F1 has no plant-like ferredoxin of its own, so an expression vector encoding the ferredoxin DmpQ from Pseudomonas CF600 (Powlowski \& Shingler, 1994), designated pDmpQ, was constructed and expressed in F1. pDmpQB, which expressed DmpQ together with its endogenous $\mathrm{C} 23 \mathrm{O}$ partner DmpB, was also created and heterologously expressed in F1. In this way, DmpQ would rescue the C23O activity of DmpB even if, by chance, it did not rescue that of TodE. An F1 strain carrying the TodE expression vector pTodE was also analysed to determine if simply increasing basal levels of the native $\mathrm{C} 23 \mathrm{O}$ enzyme of F1 could yield similar results.

Analysis of the growth cultures grown in MSM with styrene yielded surprising results (Fig. 4). Intriguingly, all F1 strains were capable of modest initial growth on styrene in the first $28 \mathrm{~h}$. By $60 \mathrm{~h}$, however, it was apparent that F1 wild-type had experienced cell death with a striking reduction in c.f.u. compared with at time 0 . At $60 \mathrm{~h}, \mathrm{~F} 1$ (pDmpQ) and F1 (pDmpB) c.f.u. counts were an order of magnitude larger than F1, but not significantly different from values at time $0(P>0.05)$. Although F1 (pDmpQ) was unable to grow on styrene, the increased c.f.u. count at $60 \mathrm{~h}$ compared with that for F1 suggested a modest protective effect. Consistent with this observation, analysis of the C23O activity of F1 (pDmpQ) following styrene exposure demonstrated that expression of DmpQ also conferred increased resistance to $\mathrm{C} 23 \mathrm{O}$ inactivation compared with F1 (Supplementary Fig. S3). Brown polymerization products were evident in all strains that

Table 2. Kinetic parameters for 6-methyl HODA and 6-vinyl HODA

Values shown are mean \pm SD of three determinations

\begin{tabular}{|lcccc|}
\hline Substrate & $\boldsymbol{K}_{\mathrm{m}}(\boldsymbol{\mu M})$ & $\boldsymbol{k}_{\text {cat }}\left(\mathbf{s}^{-\mathbf{1}}\right)$ & $\boldsymbol{V}_{\text {max }}$ & $\boldsymbol{K}_{\mathrm{cat}} / \boldsymbol{K}_{\mathrm{m}} \times \mathbf{1 0}^{-\mathbf{5}}\left(\mathbf{M}^{\mathbf{- 1}} \mathbf{s}^{\mathbf{- 1}}\right)$ \\
\hline 6-Methyl HODA & $31 \pm 3.5$ & $32 \pm 0.9$ & $63 \pm 1.8$ & $10.3 \pm 0.8$ \\
6-Vinyl HODA & $20 \pm 2.1$ & $4.8 \pm 0.14$ & $19 \pm 2.1$ & $2.4 \pm 0.18$ \\
\hline
\end{tabular}


(a)

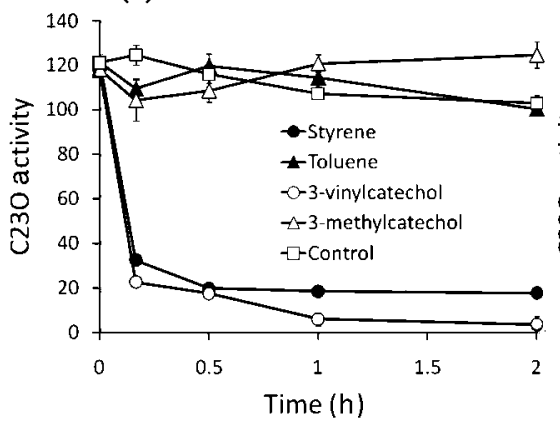

(b)

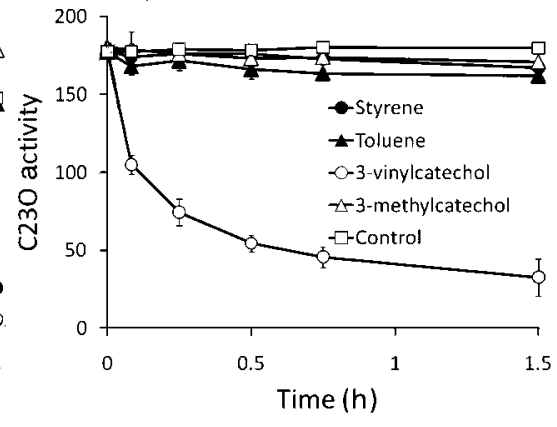

Fig. 3. $\mathrm{C} 23 \mathrm{O}$ inactivation following exposure to styrene and 3-vinylcatechol. In resting cultures of $P$. putida $\mathrm{F} 1$, exposure to either styrene or 3vinylcatechol resulted in the significant reduction of C23O activity. Neither toluene nor its metabolite 3-methylcatechol had any effect (a). In E. coli S17 (pTodE), only 3-vinylcatechol caused C23O inactivation (b). In (a) and (b), C230 activity was measured following the addition of $2 \mathrm{mM}$ catechol to washed cells (see Methods). Error bars, SD $(n=3)$. experienced a reduction in c.f.u. after $28 \mathrm{~h}$ and indicated accumulation of 3-vinylcatechol (data not shown).

Neither F1 (pDmpQB) nor F1 (pTodE), however, accumulated 3-vinylcatechol and both strains were able to grow on styrene. F1 (pTodE) grew noticeably slower than for F1 (pDmpQB), although c.f.u. counts from both strains were nearly three orders of magnitude higher than for F1 after $60 \mathrm{~h}$. Importantly, as additional evidence that TodF activity was not limiting growth on styrene, the rates of 6-vinyl HODA degradation in F1 (pDmpQB) and F1 (pTodE) were found to be identical to those for the wildtype (data not shown). Sequencing also revealed that both strains harboured wild-type todF alleles.

To gain further insight into the relationship between $\mathrm{C} 23 \mathrm{O}$ inactivation and growth, resting cultures of E. coli S17 (pDmpQB), S17 (pDmpB) and S17 (pTodE) were exposed to 3-vinylcatechol and analysed for $\mathrm{C} 23 \mathrm{O}$ activity. The initial rate of 3-vinylcatechol cleavage was highest in S17 (pDmpQB), with a C23O activity of $920 \mu \mathrm{M}(\mathrm{mg}$

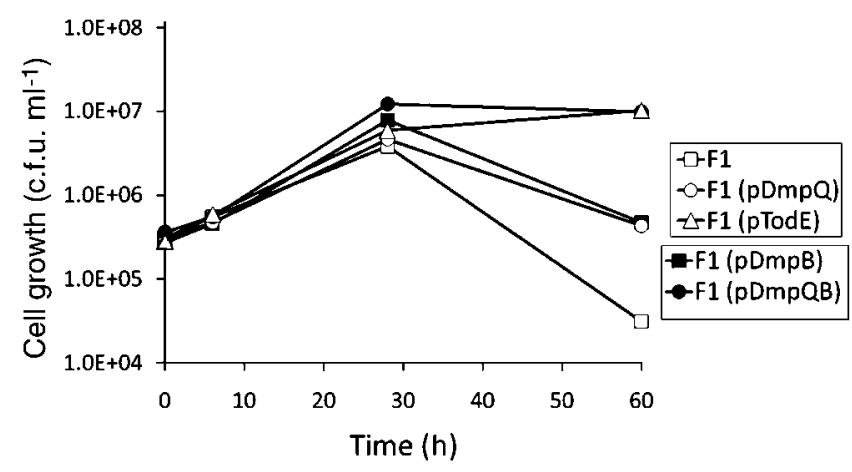

Fig. 4. Growth of F1 and recombinant strains on styrene. Although all strains initially grew on styrene, only those strains overexpressing $\mathrm{C} 23 \mathrm{O}$ s and/or a ferredoxin were able to avoid the toxicity and cell death associated with 3-vinylcatechol accumulation. All strains were grown on MSM with styrene provided in liquid phase at a concentration of $5 \mathrm{mM}$. Error bars, SD $(n=3)$, cannot be seen because they are smaller than the symbols used. protein $)^{-1} \min ^{-1}$, approximately 2.5 - and 2.0-fold higher than S17 (pTodE) and S17 (pDmpB), respectively (Fig. 5). As differences in activity could have resulted from differential protein expression or stability, inactivation behaviour following 3-vinylcatechol exposure was analysed. The inactivation behaviours of $\mathrm{S} 17$ ( $\mathrm{pDmpB}$ ) and $\mathrm{S} 17$ (pTodE) were clearly distinct: exposure to $100 \mu \mathrm{M} 3-$ vinylcatechol completely abolished $\mathrm{C} 23 \mathrm{O}$ activity in S17 (pDmpB), but S17 (pTodE) retained residual activity even after exposure to $200 \mu \mathrm{M}$ 3-vinylcatechol (Fig. 5). Intriguingly, S17 (pTodE) appeared to be even more resistant to inactivation than S17 (pDmpQB).

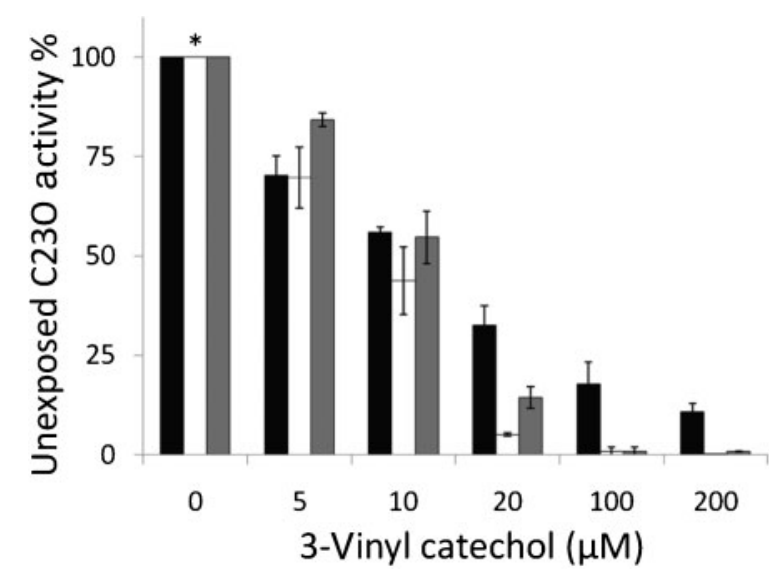

Fig. 5. $\mathrm{C} 23 \mathrm{O}$ activity and inactivation behaviour of $E$. coli strains expressing relevant $\mathrm{C} 23 \mathrm{Os}$. $\mathrm{S} 17$ (pDmpQB) (black bars) had the highest initial $\mathrm{C} 23 \mathrm{O}$ activity following exposure to 3-vinylcatechol, while S17 (pDmpB) (white bars) and S17 (pTodE) (grey bars) yielded similar activities. Despite having the lowest initial activity, TodE was more resistant than both DmpB and DmpQB to 3vinylcatechol-mediated inactivation. Measurements were taken following $30 \mathrm{~min}$ exposure to 3-vinylcatechol. Error bars, SD $(n=3)$. *Absolute values for $\mathrm{S} 17$ (pTodE), S17 (pDmpB) and $\mathrm{S} 17$ (pDmpQB) were 360,450 and $920 \mu \mathrm{M}(\mathrm{mg} \text { protein })^{-1} \mathrm{~min}^{-1}$, respectively. 


\section{DISCUSSION}

In this report we have demonstrated that the inability of $P$. putida F1 to grow on styrene is not due to the failure of TodF to metabolize the styrene MFP 6-vinyl HODA, as has been suggested previously (Cho et al., 2000). Rather, we found that 3-vinylcatechol accumulates during exposure to styrene and inactivates the C23O TodE. This inactivation prevents the conversion of 3-vinylcatechol to intermediates that can support growth, but more importantly, allows 3vinylcatechol to accumulate, causing cell death. Finally, we have shown that increasing $\mathrm{C} 23 \mathrm{O}$ expression is all that is required to prevent 3-vinylcatechol accumulation and permit F1 to grow on styrene.

Previous studies have demonstrated multiple means to expand the substrate range of aromatic degradation pathways, including mutations in regulators, recruitment of alternative catabolic enzymes and the expression of 'repair' enzymes such as [2Fe-2S] ferredoxins (Cerdan et al., 1994; Cho et al., 2000; Choi et al., 2003; Furukawa et al., 1993; Ramos et al., 1987; Rojo et al., 1987). With respect to the tod operon, work has focused on TodF and the expansion of substrate range through the recruitment of alternative MFP hydrolases, BphD (Furukawa et al., 1993) and CmtE (Choi et al., 2003).

In the current study, we specifically found that purified $\mathrm{TodF}_{\mathrm{His}}$ was able to degrade 6-vinyl HODA at a rate that was slightly lower than, but of the same order of magnitude as, 6methyl HODA. The observation that TodF degrades 6-vinyl HODA, coupled with our finding that F1 and derivatives all initially grew on styrene (Fig. 4), suggests that enough styrene was metabolized to citric acid cycle intermediates to support growth. This conclusion is also supported by our finding that F1 (pDmpQB) and F1 (pTodE), which grew well on styrene, still harboured wild-type todF alleles and activity. Together, these findings are strong evidence that TodF activity is not the factor preventing growth on styrene. Rather, the ability of the F1 derivatives overexpressing $\mathrm{C} 23 \mathrm{Os}$ to grow on styrene, together with the effect of purified 3-vinylcatechol on TodE activity, makes it clear that inactivation of TodE is responsible for the accumulation of 3 -vinylcatechol, 3-vinylcatechol toxicity and lack of net growth of F1 on styrene after $60 \mathrm{~h}$.

Interestingly, simply increasing the basal 3-vinylcatechol C23O activity in F1 twofold through expression of DmpB was not enough to permit $\mathrm{F} 1$ ( $\mathrm{pDmpB}$ ) to grow on styrene, even though a similar level of $\mathrm{C} 23 \mathrm{O}$ activity enhancement permitted growth of F1 (pTodE) (Fig. 4). Further analysis suggested that this was because DmpB was actually more sensitive to the deactivating affects of 3-vinylcatechol than TodE even though they had similar initial activity (Fig. 5). When co-expressed with its endogenous ferredoxin DmpQ, $\mathrm{DmpB}$ was more resistant to inactivation (Fig. 5) and cleaved approximately twofold more 3-vinylcatechol per milligram protein prior to complete inactivation (Supplementary Fig. S4). These differences in inactivation behaviour are clearly reflected in the growth curve presented in
Fig. 4 and suggest a dose-response relationship between catechol turnover and growth on styrene.

Catechols can initiate toxicity through a wide range of molecular mechanisms, including the production of reactive oxygen species (Schweigert et al., 2001), and it is likely that accumulation of 3-vinylcatechol following C23O inhibition had toxic consequences. Although physiological end points were not a focus of this work, the noted decrease in c.f.u. in strains harbouring the C23Os that were most prone to inactivation (Figs 4 and 5) points to cell death and implicates 3-vinylcatechol as the probable cause of toxicity. In certain aromatic degradation systems, catechol toxicity is avoided by preferentially increasing the rate of catechol-consuming rather than catecholproducing reactions through duplication of catechol dioxygenase genes. In this manner, catechol intermediates do not accumulate and potential toxicity is avoided. It was shown that in Ralstonia eutropha JMP134(pJP4), multiple copies of $t f d C$ (chlorocatechol 1,2-dioxygenase) were required for efficient 3-chlorocatechol turnover and growth on 3-chlorobenzoic acid (Laemmli et al., 2000; PérezPantoja et al., 2003; Trefault et al., 2004). A reduction in $t f d C$ copy number inhibited growth on 3-chlorobenzoic acid, as did an increase in 3-chlorocatechol production. In another study, the predominant organism in a chlorobenzenecontaminated aquifer, Ralstonia JS745, was found to utilize a mosaic pathway containing partially duplicated $c l c A$ genes responsible for chlorocatechol degradation (Müller et al., 2003; van der Meer et al., 1998). Intriguingly, the upper pathway in JS745 was highly homologous to the genes encoding toluene dioxygenase $(\operatorname{tod} C 1 C 2 B A D)$ in $\mathrm{F} 1$. Although both $t f d C$ and $c l c A$ encode ortho- rather than meta-cleaving dioxygenases, these studies underline the importance of efficient catechol consumption as a means for substrate expansion. In our current work, increasing the expression of TodE - thus mimicking gene duplication - was enough to confer growth on styrene and reduce toxicity.

Other aromatic pathways may achieve similar results through uncoupled regulation of the upper pathway, which is responsible for initial dioxygenation and catechol production, and of the lower pathway, which is responsible for catechol degradation. Indeed, both the nah and $b p h$ operons for naphthalene and biphenyl degradation, respectively, contain multiple LysR-type regulator binding sites which allow for independent transcription of upper and lower pathway genes (Huang \& Schell, 1991; Watanabe et al., 2003, 2000). The importance of regulating relative levels of catechol degradation activity was hinted at by Park \& Madsen (2004) who have shown that regulation by NahR, which preferentially upregulates the lower pathway genes encoding degradation of catechol, was critical for the survival of naphthalene degraders in naphthalene-contaminated soil. This contrasts with the monocistronic nature of the tod operon and the absence of a supplementary promoter directly upstream of todE.

Our work with styrene suggests that the coupled regulation of the upper and lower pathways in the tod operon might 
be one factor limiting growth substrate range and suggests why a modular strategy for control of the upper and lower pathways might confer selective advantages on organisms trying to exploit diverse aromatic substrates for growth. Interestingly, in many sphingomonads, which are known for their ability to use a wide range of aromatic substrates for growth, the upper and lower pathways appear as distinct modules and are not co-ordinately regulated. In many cases they are not even found in the same region of the genome (Armengaud et al., 1998; Kim \& Zylstra, 1999). The need to avoid the production of deactivating catechols may also have contributed to the evolutionary pressure that resulted in the emergence of an alternative pathway for styrene degradation that relies on a styrene monooxygenase and leads to phenylacetic acid (Mooney et al., 2006). In this pathway, catechol is not produced and the hydroxylated ring is cleaved hydrolytically rather than oxidatively.

This work helps to clarify the role of TodF in styrene metabolism and clearly demonstrates that accumulation and toxicity of 3-vinylcatechol rather than failure to metabolize 6-vinyl HODA is what prevents F1 from growing on styrene. Our results are consistent with the need of cells to avoid catechol accumulation and provide the first evidence for TodE inactivation by 3 -alkylcatechols. This was clearly demonstrated by our ability to enhance the range of substrates F1 uses for growth by simply overexpressing C23Os, and may help to explain further the value of modular genetic strategies employed by many bacteria that grow on a wide array of aromatic substrates.

\section{ACKNOWLEDGEMENTS}

We gratefully acknowledge Dr Gerben Zylstra for providing P. putida F1 and pDTG601. Thanks to Dr Eugene Madsen for sharing facilities and providing experimental guidance. This work was supported in part by the New York State Center for Advanced Technology. K.W.G. was supported in part by a fellowship from the Paracelsian Fund. J. K. was supported by a predoctoral fellowship from the Howard Hughes Medical Institute.

\section{REFERENCES}

Armengaud, J., Happe, B. \& Timmis, K. N. (1998). Genetic analysis of dioxin dioxygenase of Sphingomonas sp. strain RW1: catabolic genes dispersed on the genome. J Bacteriol 180, 3954-3966.

Baker, G. B., Coutts, R. T. \& Holt, A. (1994). Derivatization with acetic anhydride: applications to the analysis of biogenic-amines and psychiatric drugs by gas-chromatography and mass-spectrometry. J Pharmacol Toxicol Methods 31, 141-148.

Bartels, I., Knackmuss, H. J. \& Reineke, W. (1984). Suicide inactivation of catechol 2,3-dioxygenase from Pseudomonas putida mt-2 by 3-halocatechols. Appl Environ Microbiol 47, 500-505.

Busch, A., Lacal, J., Martos, A., Ramos, J. L. \& Krell, T. (2007). Bacterial sensor kinase TodS interacts with agonistic and antagonistic signals. Proc Natl Acad Sci U S A 104, 13774-13779.

Cerdan, P., Wasserfallen, A., Rekik, M., Timmis, K. N. \& Harayama, S. (1994). Substrate-specificity of catechol 2,3-dioxygenase encoded by
TOL plasmid PWWO of Pseudomonas putida and its relationship to cell growth. J Bacteriol 176, 6074-6081.

Cho, M. C., Kang, D. O., Yoon, B. D. \& Lee, K. (2000). Toluene degradation pathway from Pseudomonas putida F1: substrate specificity and gene induction by 1 -substituted benzenes. $J$ Ind Microbiol Biotechnol 25, 163-170.

Choi, E. N., Cho, M. C., Kim, Y., Kim, C. K. \& Lee, K. (2003). Expansion of growth substrate range in Pseudomonas putida F1 by mutations in both $c y m R$ and todS, which recruit a ring-fission hydrolase $\mathrm{CmtE}$ and induce the tod catabolic operon, respectively. Microbiology 149, 795805.

de Lorenzo, V. \& Timmis, K. N. (1994). Analysis and construction of stable phenotypes in Gram-negative bacteria with Tn5-derived and Tn10-derived minitransposons. Methods Enzymol 235, 386-405.

Diaz, E. (2004). Bacterial degradation of aromatic pollutants: a paradigm of metabolic versatility. Int Microbiol 7, 173-180.

Focht, D. D. (1994). Microbial procedures for biodegradation research. In Methods of Soil Analysis, Part 2. Microbiological and Biochemical Properties, pp. 407-426. Edited by R. W. Weaver, J. S. Angle \& P. S. Bottomley. Madison, WI: Soil Science Society of America.

Furukawa, K., Hirose, J., Suyama, A., Zaiki, T. \& Hayashida, S. (1993). Gene components responsible for discrete substrate specificity in the metabolism of biphenyl ( $b p h$ operon) and toluene (tod operon). J Bacteriol 175, 5224-5232.

Fushinobu, S., Saku, T., Hidaka, M., Jun, S. Y., Nojiri, H., Yamane, H., Shoun, H., Omori, T. \& Wakagi, T. (2002). Crystal structures of a meta-cleavage product hydrolase from Pseudomonas fluorescens IP01 (CumD) complexed with cleavage products. Protein Sci 11, 21842195.

Gibson, D. T., Koch, J. R. \& Kallio, R. E. (1968). Oxidative degradation of aromatic hydrocarbons by microorganisms. I. Enzymatic formation of catechol from benzene. Biochemistry 7, 2653-2662.

Habe, H., Morii, K., Fushinobu, S., Nam, J. W., Ayabe, Y., Yoshida, T., Wakagi, T., Yamane, H., Nojiri, H. \& other authors (2003). Crystal structure of a histidine-tagged serine hydrolase involved in the carbazole degradation (CarC enzyme). Biochem Biophys Res Commun 303, 631-639.

Hanahan, D. (1983). Studies on transformation of Escherichia coli with plasmids. J Mol Biol 166, 557-580.

Huang, J. Z. \& Schell, M. A. (1991). In vivo interactions of the NahR transcriptional activator with its target sequences: inducer-mediated changes resulting in transcription activation. J Biol Chem 266, 1083010838.

Hugo, N., Armengaud, J., Gaillard, J., Timmis, K. N. \& Jouanneau, Y. (1998). A novel [2Fe-2S] ferredoxin from Pseudomonas putida mt-2 promotes the reductive reactivation of catechol 2,3-dioxygenase. J Biol Chem 273, 9622-9629.

Hugo, N., Meyer, C., Armengaud, J., Gaillard, J., Timmis, K. N. \& Jouanneau, Y. (2000). Characterization of three XylT-like [2Fe-2S] ferredoxins associated with catabolism of cresols or naphthalene: evidence for their involvement in catechol dioxygenase reactivation. J Bacteriol 182, 5580-5585.

Jiang, H. Y., Parales, R. E., Lynch, N. A. \& Gibson, D. T. (1996). Sitedirected mutagenesis of conserved amino acids in the alpha subunit of toluene dioxygenase: potential mononuclear non-heme iron coordination sites. J Bacteriol 178, 3133-3139.

Jiang, H. Y., Parales, R. E. \& Gibson, D. T. (1999). The alpha subunit of toluene dioxygenase from Pseudomonas putida F1 can accept electrons from reduced ferredoxin (TOL) but is catalytically inactive in the absence of the beta subunit. Appl Environ Microbiol 65, 315318. 
Kim, E. \& Zylstra, G. J. (1999). Functional analysis of genes involved in biphenyl, naphthalene, phenanthrene, and m-xylene degradation by Sphingomonas yanoikuyae B1. J Ind Microbiol Biotechnol 23, 294302.

Klecka, G. M. \& Gibson, D. T. (1981). Inhibition of catechol 2,3dioxygenase from Pseudomonas putida by 3-chlorocatechol. Appl Environ Microbiol 41, 1159-1165.

Kovach, M. E., Elzer, P. H., Hill, D. S., Robertson, G. T., Farris, M. A., Roop, R. M., II \& Peterson, K. M. (1995). Four new derivatives of the broad-host-range cloning vector pBBR1MCS, carrying different antibiotic-resistance cassettes. Gene 166, 175-176.

Kroll, D. J., Abdelhafiz, H. A., Marcell, T., Simpson, S., Chen, C. Y., Gutierrezhartmann, A., Lustbader, J. W. \& Hoeffler, J. P. (1993). A multifunctional prokaryotic protein expression system: overproduction, affinity purification, and selective detection. DNA Cell Biol 12, 441-453.

Lacal, J., Busch, A., Guazzaroni, M. E., Krell, T. \& Ramos, J. L. (2006). The TodS-TodT two-component regulatory system recognizes a wide range of effectors and works with DNA-bending proteins. Proc Natl Acad Sci U S A 103, 8191-8196.

Lacal, J., Guazzaroni, M. E., Busch, A., Krell, T. \& Ramos, J. L. (2008). Hierarchical binding of the TodT response regulator to its multiple recognition sites at the tod pathway operon promoter. J Mol Biol 376, 325-337.

Laemmli, C. M., Leveau, J. H. J., Zehnder, A. J. B. \& van der Meer, J. R. (2000). Characterization of a second $t f d$ gene cluster for chlorophenol and chlorocatechol metabolism on plasmid pJP4 in Ralstonia eutropha JMP134(pJP4). J Bacteriol 182, 4165-4172.

Lau, P. C., Wang, Y., Patel, A., Labbe, D., Bergeron, H., Brousseau, R., Konishi, Y. \& Rawlings, M. (1997). A bacterial basic region leucine zipper histidine kinase regulating toluene degradation. Proc Natl Acad Sci U S A 94, 1453-1458.

Menn, F. M., Zylstra, G. J. \& Gibson, D. T. (1991). Location and sequence of the todF gene encoding 2-hydroxy-6-oxohepta-2,4dienoate hydrolase in Pseudomonas putida F1. Gene 104, 91-94.

Mooney, A., Ward, P. G. \& O'Connor, K. E. (2006). Microbial degradation of styrene: biochemistry, molecular genetics, and perspectives for biotechnological applications. Appl Microbiol Biotechnol 72, $1-10$.

Mosqueda, G., Ramos-Gonzalez, M. I. \& Ramos, J. L. (1999). Toluene metabolism by the solvent-tolerant Pseudomonas putida DOT-T1 strain, and its role in solvent impermeabilization. Gene 232, 69-76.

Müller, T. A., Werlen, C., Spain, J. \& van der Meer, J. R. (2003). Evolution of a chlorobenzene degradative pathway among bacteria in a contaminated groundwater mediated by a genomic island in Ralstonia. Environ Microbiol 5, 163-173.

Nandhagopal, N., Yamada, A., Hatta, T., Masai, E., Fukuda, M., Mitsui, Y. \& Senda, T. (2001). Crystal structure of 2-hydroxyl-6-oxo6-phenylhexa-2,4-dienoic acid (HPDA) hydrolase (BphD enzyme) from the Rhodococcus sp. strain RHAl of the PCB degradation pathway. J Mol Biol 309, 1139-1151.

Ohta, Y., Maeda, M. \& Kudo, T. (2001). Pseudomonas putida CE2010 can degrade biphenyl by a mosaic pathway encoded by the tod operon and $c m t E$, which are identical to those of $P$. putida F1 except for a single base difference in the operator-promoter region of the $\mathrm{cmt}$ operon. Microbiology 147, 31-41.

Park, W. \& Madsen, E. L. (2004). Characterization in Pseudomonas putida Cg1 of nahR and its role in bacterial survival in soil. Appl Microbiol Biotechnol 66, 209-216.

Pérez-Pantoja, D., Ledger, T., Pieper, D. H. \& Gonzalez, B. (2003). Efficient turnover of chlorocatechols is essential for growth of
Ralstonia eutropha JMP134(pJP4) in 3-chlorobenzoic acid. J Bacteriol 185, 1534-1542.

Polissi, A. \& Harayama, S. (1993). In vivo reactivation of catechol 2,3dioxygenase mediated by a chloroplast-type ferredoxin: a bacterial strategy to expand the substrate-specificity of aromatic degradative pathways. EMBO J 12, 3339-3347.

Powlowski, J. \& Shingler, V. (1994). Genetics and biochemistry of phenol degradation by Pseudomonas sp. CF600. Biodegradation 5, 219-236.

Ramos, J. L., Wasserfallen, A., Rose, K. \& Timmis, K. N. (1987). Redesigning metabolic routes: manipulation of TOL plasmid pathway for catabolism of alkylbenzoates. Science 235, 593-596.

Rojo, F., Pieper, D. H., Engesser, K. H., Knackmuss, H. J. \& Timmis, K. N. (1987). Assemblage of ortho cleavage route for simultaneous degradation of chloro- and methylaromatics. Science 238, 13951398.

Schweigert, N., Zehnder, A. J. B. \& Eggen, R. I. L. (2001). Chemical properties of catechols and their molecular modes of toxic action in cells, from microorganisms to mammals. Environ Microbiol 3, 81-91.

Seah, S. Y. K., Terracina, G., Bolin, J. T., Riebel, P., Snieckus, V. \& Eltis, L. D. (1998). Purification and preliminary characterization of a serine hydrolase involved in the microbial degradation of polychlorinated biphenyls. J Biol Chem 273, 22943-22949.

Seah, S. Y. K., Labbe, G., Nerdinger, S., Johnson, M. R., Snieckus, V. \& Eltis, L. D. (2000). Identification of a serine hydrolase as a key determinant in the microbial degradation of polychlorinated biphenyls. J Biol Chem 275, 15701-15708.

Shingler, V., Powlowski, J. \& Marklund, U. (1992). Nucleotide sequence and functional analysis of the complete phenol/3,4dimethylphenol catabolic pathway of Pseudomonas sp. strain CF600. J Bacteriol 174, 711-724.

Trefault, N., De la Iglesia, R., Molina, A. M., Manzano, M., Ledger, T., Pérez-Pantoja, D., Sanchez, M. A., Stuardo, M. \& Gonzalez, B. (2004). Genetic organization of the catabolic plasmid pJP4 from Ralstonia eutropha JMP134 (pJP4) reveals mechanisms of adaptation to chloroaromatic pollutants and evolution of specialized chloroaromatic degradation pathways. Environ Microbiol 6, 655-668.

Vaillancourt, F. H., Labbe, G., Drouin, N. M., Fortin, P. D. \& Eltis, L. D. (2002). The mechanism-based inactivation of 2,3-dihydroxybiphenyl 1,2-dioxygenase by catecholic substrates. J Biol Chem 277, 20192027.

Vaillancourt, F. H., Bolin, J. T. \& Eltis, L. D. (2006). The ins and outs of ring-cleaving dioxygenases. Crit Rev Biochem Mol Biol 41, 241267.

van der Meer, J. R., Werlen, C., Nishino, S. F. \& Spain, J. C. (1998). Evolution of a pathway for chlorobenzene metabolism leads to natural attenuation in contaminated groundwater. Appl Environ Microbiol 64, 4185-4193.

Ward, G., Parales, R. E. \& Dosoretz, C. G. (2004). Biocatalytic synthesis of polycatechols from toxic aromatic compounds. Environ Sci Technol 38, 4753-4757.

Watanabe, T., Inoue, R., Kimura, N. \& Furukawa, K. (2000). Versatile transcription of biphenyl catabolic bph operon in Pseudomonas pseudoalcaligenes KF707. J Biol Chem 275, 31016-31023.

Watanabe, T., Fujihara, H. \& Furukawa, K. (2003). Characterization of the second LysR-type regulator in the biphenyl catabolic gene cluster of Pseudomonas pseudoalcaligenes KF707. J Bacteriol 185, 35753582.

Yanisch-Perron, C., Vieira, J. \& Messing, J. (1985). Improved M13 phage cloning vectors and host strains: nucleotide sequences of the M13mp18 and pUC19 vectors. Gene 33, 103-119. 
Yeh, W. K., Gibson, D. T. \& Liu, T. N. (1977). Toluene dioxygenase: multicomponent enzyme system. Biochem Biophys Res Commun 78, 401-410.

Zylstra, G. J. \& Gibson, D. T. (1989). Toluene degradation by Pseudomonas putida F1: Nucleotide sequence of the todC1C2BADE genes and their expression in Escherichia coli. J Biol Chem 264, 14940-14946.
Zylstra, G. J., McCombie, W. R., Gibson, D. T. \& Finette, B. A. (1988). Toluene degradation by Pseudomonas putida F1: genetic organization of the tod operon. Appl Environ Microbiol 54, 1498-1503.

Edited by: D. J. Arp 